\title{
Wissenschaftsgeschichte
}

\section{Das Mendelianum - Ort der Dokumentation der Genetik-Geschichte}

\author{
MICHAL V. SIMUNEK ${ }^{1}$, UWE HOßFELD ${ }^{2}$, JIRÍ SEKERÁK ${ }^{3}$ \\ ${ }^{1}$ INSTITUT FÜR ZEITGESCHICHTE DER AKADEMIE DER WISSENSCHAFTEN, PRAG, TSCHECHIEN \\ 2 ARBEITSGRUPPE BIOLOGIEDIDAKTIK, UNIVERSITÄT JENA \\ ${ }^{3}$ MÄHRISCHES LANDESMUSEUM, BRÜNN, TSCHECHIEN
}

DOI: 10.1007/s12268-018-0973-y

(C) Springer-Verlag 2018

Der Augustiner-Mönch und Abt Gregor J. Mendel (1822-1884), der in der mährischen Landeshauptstadt Brno (Brünn) lebte und wirkte, veröffentlichte im Jahr 1865 seine Theorie zur Entstehung und Entwicklung von Pflanzenhybriden. Mendel untermauerte seine Arbeit durch jahrelange sorgfältige Versuche mit Erbsen und anderen Pflanzen im Garten des Augustinerklosters in Alt Brünn.

Schon früh gab es in Brünn Bestrebungen, die wissenschaftlichen Leistungen Mendels

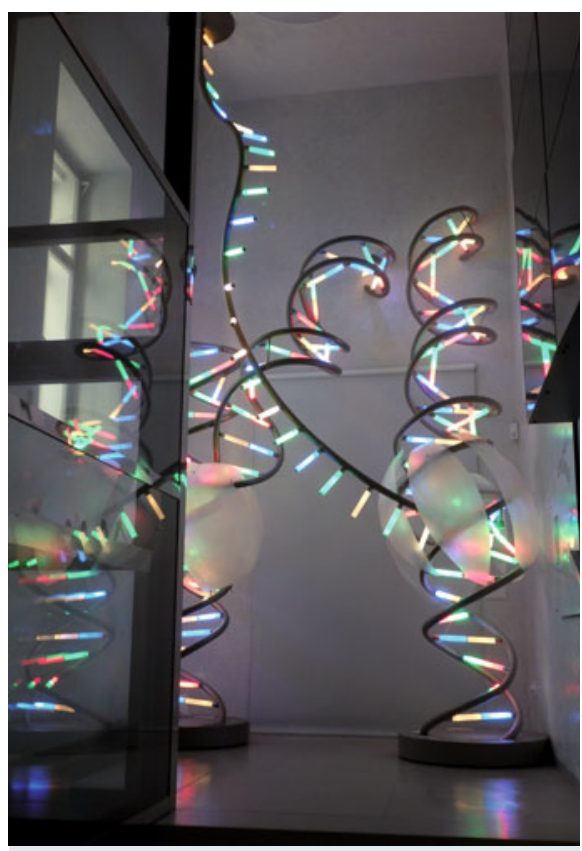

$\Delta$ Abb.: Den Besucher des Mendelianum empfängt ein Modell der DNA gleich im Eingangsbereich. zu dokumentieren, etwa in den 1920er und 1930er Jahren durch den Biographen Hugo Iltis (1882-1952). Anlässlich des 100. Jubiläums von Mendels Veröffentlichung wurde 1965 mit der Konzeption eines Symposiums in Brünn unter der Mitarbeit der Tschechoslowakischen Akademie der Wissenschaften und der tschechoslowakischen Kommission der UNESCO begonnen. Ergebnis war die Etablierung eines Dokumentationszentrum zur Geschichte der Genetik. Dieses Zentrum wurde als eine eigene Abteilung an das Mährische Landesmuseum angegliedert, mit der Aufgabe, die Genetik des 20. Jahrhundert zu dokumentieren und archivieren. Seit 1965 wurde zudem die Fachzeitschrift Folia Mendeliana herausgegeben.

Das „Mendelianum“ wurde im Kloster in Alt Brünn, dem ursprünglichen Wirkungsort von Mendel, eingerichtet. An diesem Ort blieb die Ausstellung bis zum Jahr 2001. Als Folge der Rückgabe von kirchlichem Eigentum wurde die ursprüngliche Ausstellung jedoch danach wieder abgebaut und fand erst im Jahr 2014 neue Ausstellungsräume im Bischofshof, einem gotischen Gebäude der Probstei des Brünner Kapitels im Stadtzentrum, wo Mendel seit 1854 u.a. als Bibliothekar tätig gewesen war. Hier wird nun die Geschichte der Genetik einer breiten Öffentlichkeit zugänglich gemacht. Neben der Ausstellung wurden auch interaktive Labors eingerichtet. Dank der Verknüpfung historischer Räumlichkeiten, wo der „Vater der Genetik” tätig war, mit einem modern ausgestatteten Labor, können die Besucher zahlreiche Methoden und Laborverfahren selbst ausprobieren, z. B. die Bestäubung der Erbsenblüten bis hin zur Genexpression. Neben den Exponaten aus den Lebzeiten Mendels, z. B. Mendels persönliche Korrespondenz und Fotografien, ist eine Bibliothek sowie ein Archiv mit ca. 22.000 Büchern und Veröffentlichungen aus allen Bereichen der aktuellen genetischen und molekulargenetischen Forschung zugänglich.

Ein Besuch des Mendelianums und der Wirkungsstätte Mendels in Brünn lohnt sich also auch noch im 21. Jahrhundert!

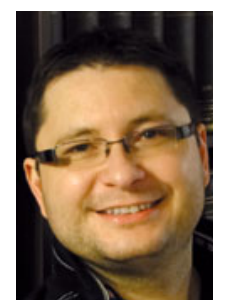

Korrespondenzadresse:

Dr. Michal V. Simunek

Akademie der Wissenschaften (AdW)

Institut für Zeitgeschichte der AdW Prag

Abteilung für Wissenschaftsgeschichte

Puškinovo nám. 9

CZ-16000 Praha 6

Tel.: 0042-(0)219-906-122

simunekm@centrum.cz 